\title{
Interação mãe e filho: um percurso através da análise do discurso para a compreensão do retardo de linguagem
}

\author{
Mother and son interaction: a journey through discourse \\ analysis into the comprehension of language impairment
}

\section{Beatriz Helena Vieira Maranghetti Ferriolli Universidade de Ribeirão Preto Melodi Witt Secretaria Municipal de Saúde de Barretos}

\section{Resumo}

Ancorado na Análise do Discurso de linha francesa, este artigo tem como objetivo descrever os processos dialógicos entre uma mãe e seu filho de dois anos, que apresenta retardo de linguagem. A interação foi filmada, transcrita e analisada de acordo com a Análise de Discurso francesa. Os resultados mostraram um movimento (inconsciente) da mãe no sentido de conter a iniciativa do filho. A mãe ocupou todos os turnos discursivos e encaminhou o sentido da "brincadeira" para os lugares de seu desejo, colocando a criança em um lugar de silêncio. Concluímos que a criança com atraso de linguagem é representada como incapaz e passa a ocupar um lugar discursivo de dependência em relação ao outro (que fala e age por ela). Dessa "posição-sujeito", fica difícil a criança adquirir autonomia e ser autora de suas iniciativas.

\section{Palavras-chave}

Atraso de linguagem, Linguagem infantil, Família, Análise do discurso francesa 


\section{Abstract}

Grounded on French Discourse Analysis, this article aims to describe the dialogical processes between a mother and her two-year-old son, who presents language impairment. The interaction was videorecorded, and the speech was later transcribed and analyzed following French Discourse Analysis. The results showed an unconscious move by the mother into restraining her son's initiative. The mother took every discursive turn and conducted the course of the "game" into wherever she wished, leaving the child in a silent condition. We conclude that the language-impaired child is represented as incapable and is thus assigned a discursive place of dependency in regard with the other (the one who speaks and acts for him). From this "subject position", it becomes difficult for the child to gain autonomy and act as an author of his initiatives.

\section{Keywords}

Language Impairment, Child Language, Family, French Discourse Analysis 


\section{Introdução}

o estudar a linguagem da criança, é frequente nos questionarmos sobre
os motivos de tantas variáveis no processo de aquisição da língua pelo
sujeito.

Desde muito cedo no percurso de construção linguística da criança, existem significantes nos discursos dos pais que indiciam um provável retardo de linguagem (TFOUNI et al., 2002). Daí a importância da atenção do clínico ao discurso dos familiares, para uma compreensão mais ampla dos sintomas das crianças.

Para melhor entendimento das relações dialógicas entre pais e filhos e, consequentemente, a respeito de sua influência sobre a constituição, não só linguística, mas também identitária dessas crianças, é necessário que essa discussão esteja alicerçada na noção de dialogismo e mediação entre o adulto e a criança na relação com o mundo. Nesse sentido, o adulto, por meio de sua linguagem, seus gestos, expressões e atitudes, simboliza para a criança o mundo e seu funcionamento linguístico, mostrando, predominantemente, uma simetria dialógica ou a antítese desta.

Por meio da linguagem, os pais mostram sua subjetividade e, dessa forma, evidenciam quais são os lugares possíveis de seus filhos existirem como sujeitos da e na linguagem. “(...) Nossa individualidade não teria existência se o outro não a criasse" (KOMESU, 2002,p. 55). A representação que os pais fazem dessa criança a colocará em determinados lugares discursivos e não em outros, permeando todas as demais relações e opções que ela possa vir a ter (TFOUNI, op . cit.). A força da determinação é que irá sofrer uma variação, dependendo da liberdade (relativa) que o sujeito conquista em suas relações interpessoais.

Quando o adulto usa expressões como: "Olha que engraçadinha!', "Ele é a cara do vovô!", "Ele gagueja desde os 10 meses igual ao pai”, e assim por diante, está mostrando qual é o lugar possível de essa criança se constituir. Pela linguagem demonstramos quais são nossos ideais, recalques, frustrações, desejos de realizações. Tais materialidades passam a ser verbalizadas e/ou 
demonstradas por meio de gestos, olhares, entonações e, como todos nós estamos inseridos em uma cultura, assimilamos os hábitos, os valores, as críticas, as censuras, os ideais da sociedade.

Assim, todos os nossos conteúdos linguísticos são atravessados por valores culturais que são ideológicos (ORLANDI, 1999). Isso porque não há discurso sem sujeito e não há sujeito sem ideologia (ORLANDI, 1999; TFOUNI; PANTONI, 2004), e ambos encontram-se ligados pela língua. A língua reverbera para cada sujeito de uma forma, por isso cada filho é de um jeito e cada sujeito, por mais semelhante que seja, guarda a sua singularidade (FERRIOLLI, 2007) e, reverberando, cria uma memória (aqui compreendida como interdiscurso) ligada à historicidade de cada sujeito e, portanto, a conteúdos ideológicos.

Como a ideologia é "construída" junto com a linguagem (e ambas são constitutivas do sujeito), é possível de ser identificada pela materialidade da língua, ou seja, no dizer do sujeito é que ele atribui sentido(s) ao mundo como se fosse o único modo de interpretação possível (PÊCHEUX, 1997).

A criança, quando pequena, encontra-se submersa no interdiscurso que compartilha com os demais sujeitos. Através dessa via é que passará por um processo de subjetivação, que é o seu caminho de constituição como sujeito linguístico. Ferraz e Ferraz (2001) explica que essa é uma condição de dependência da criança em relação ao adulto e que aos poucos irá se transformar "em posição discursiva quando a criança passa a ser intérprete do outro, de si própria e da linguagem como geradora de significado e intenção" (p.13). Esse processo culmina em se perceber e assumir o centro do discurso. Se isso não ocorre, ocupa-se a posição (no discurso) que o outro lhe reserva, que é o caso da criança no início da aquisição da linguagem ou daquelas que apresentam retardo de linguagem.

Buscar a historicidade do sujeito, por meio do que nos conta sua família, é um ponto fundamental, que poderá revelar questões sobre a gênese do distúrbio. Assim, nós, fonoaudiólogos, precisamos, como fonoaudiólogos, exercitar uma escuta clínica voltada para aspectos discursivos do sujeito que reverberem sentidos "familiares". Também necessitamos de suporte teórico consistente para analisarmos a fala e a linguagem da criança com base nas relações que ela possui com a sua origem - o discurso de seus pais.

Estudos mais recentes (SACHSE; VON SUCHODOLETZ, 2008; RESCORLA et al., 2007) na área do Retardo de Linguagem têm valorizado o papel dos pais nas relações comunicativas e emocionais das crianças. Em relação 
ao nosso relato, tivemos interesse em estabelecer as implicações entre a dialogia preestabelecida desde muito cedo entre os pais e as crianças com Retardo de Linguagem.

Aqui, a linguagem está sendo entendida como uma construção simbólica que se inicia, para a criança, mesmo antes de ela nascer (FERRIOLLI, 2003). $\mathrm{O}$ adulto fará o papel de mediador entre a criança e o mundo real, sendo que objetos e situações serão falados, descritos e interpretados por esse adulto. Para a criança ficará impressa, de alguma forma, a noção de mundo perpassada pelo adulto.

A criança é concebida como posição que ocupa no interior da estrutura discursiva familiar. Tal como o valor do signo linguístico não depende apenas do que ele é por si mesmo, mas, sobretudo, da posição que ocupa em relação aos outros elementos do conjunto (SAUSSURE, 1975); o sujeito, na dinâmica familiar, também deve ser compreendido como uma posição, pois seus enunciados serão proferidos a partir dos lugares possíveis a ele em suas relações interpessoais. A atitude de cada um irá ecoar no outro e provocar, a seu tempo, uma resposta.

Assim, a linguagem é uma forma de o eu simbolizar-se na (a tu)ação com os seus semelhantes, um modo singular de construção da subjetividade (AUTHIERREVUZ, 1990). Por isso, é possível falar em interlocutores e discursos heterogêneos, visto que cada sujeito, mobilizado pelo inconsciente, se constitui com base em suas vivências e por meio das representações (imaginárias) que faz de seus parceiros interacionais.

Nessa perspectiva, algumas autoras (TFOUNI; FERRIOLLI; MORAES, 2002; PALLADINO, 1999 e SOBRINHO, 1996, entre outras) consideram seu objeto de estudo heterogêneo e opaco, o que torna possível ao clínico olhar para o discurso como incompleto, falho e com lacunas. O discurso passa a ser entendido como fragmentos de um objeto inesgotável, com muitos sentidos possíveis. No caso deste estudo, entendemos o discurso como um acontecimento que emerge do encontro entre interlocutores.

Sob essa ótica, os papéis na clínica fonoaudiológica são interpretados como dialéticos, pois se constroem na relação e não a priori. Isso nos possibilita lidar com o que o sujeito nos traz, já que a relação é via significação (de uma fala ou de um silêncio) e, assim, o papel da clínica passa a ser o da investigação/ interpretação de indícios dos processos discursivos ou do acontecimento. Num movimento constante entre falar/calar, compartilhar/divergir, distanciar/aproximar 
se instauram lugares novos e possíveis para a criança deixar sua posição latente e ocupar, também, um lugar ativo de falante e autor.

Ao entender que a linguagem é faltosa, incompleta e que é preciso se ancorar no outro, o clínico passa a ter condições de auxiliar o sujeito a instaurar outras posições e, consequentemente, a elaborar diferentes formações discursivas (FOUCAULT, 2004). Isso porque os referenciais aprendidos pelo sujeito, a partir de seu contexto sociocultural e ideológico, levam-no a ocupar um determinado lugar discursivo que para ele é a sua região de linguagem, possível de existir, pensar sobre si e os outros. É o lugar em que ele se reconhece e por meio do qual olha, escuta e analisa seu interlocutor.

Assim, o sujeito não é livre para ocupar qualquer "dizer", mas encontrase "autodeterminado" pelo dizer do outro/Outro (LACAN, 1998). O outro está sempre relacionado à noção de alteridade e pode estar presentificado (ou não) empiricamente; pode remeter, por exemplo, à mãe, ao pai, ao professor, ao irmão mais velho. Já, o Outro (LACAN, 1998) (com “O” maiúsculo) remete a um lugar simbólico, virtual, que, segundo a psicanálise lacaniana, impera sobre a cadeia significante do sujeito.

Nosso objetivo é analisar, com base em um paradigma histórico-discursivo, a interação de uma mãe com seu filho de dois anos de idade, que apresenta um Retardo de Linguagem. Acreditamos que este trabalho se justifica pelo interesse crescente que a fonoaudiologia vem demonstrando em relação a estudos que mantêm seu foco em abordagens discursivas, em especial as que centralizam disciplinas indiciárias, como a Análise de Discurso pecheutiana e a Psicanálise lacaniana (TFOUNI; FERRIOLLI, 2008).

\section{Apresentação do caso clínico}

São sujeitos desta pesquisa uma criança (João - nome fictício) de dois anos e um mês, que apresentava queixa de "atraso na fala", e sua mãe. Por meio de uma avaliação fonoaudiológica, foi diagnosticado um Retardo de Linguagem. Na ocasião do estudo, os pais estavam separados e a mãe não lidava bem com esse fato, de acordo com o seu discurso, pois foi o marido que saiu de casa e constituiu nova família. Além do João, o casal tem uma filha de seis anos.

Esta pesquisa foi apresentada ao Comitê de Ética em Pesquisa da Universidade de Ribeirão Preto e cadastrada com o número 147/07. A mãe assinou o Termo de Consentimento Livre e Esclarecido. 
A filmagem ocorreu no próprio consultório de uma das pesquisadoras. Os dados foram transcritos ortograficamente de acordo com as normas do Projeto NURC - Norma Linguística Urbana Culta (PRETI, 2001). Foi aplicada a Análise de Discurso (AD) de linha francesa em recortes privilegiados de acordo com a proposta deste estudo, ou seja, naquelas materialidades que indiciam o lugar em que a criança é "posta" pela mãe. Para citar alguns exemplos: uso de substantivos no Grau Diminutivo e verbos no Modo Imperativo; enunciados da mãe nos quais ela se antecipa à criança; deslocamentos de um substantivo a outro. Além dessas substancialidades linguísticas, também foram consideradas as atitudes da mãe e da criança durante situações de "brincar livre", enfatizando que gestos e expressões também são constitutivos do discurso.

Os recortes discursivos são unidades significativas do discurso, privilegiados pelo pesquisador porque deflagram um modo específico de funcionamento discursivo, revelando o lugar de produção de sentido do enunciado (COURTINE, 1984). Ao se considerar a interação mãe-filho como um acontecimento discursivo, não é possível antever as unidades a serem recortadas e analisadas. Dito de outro modo, a interpretação não é anterior aos dados linguísticos e extraverbais da interação.

Legenda: $\mathbf{M}$ - mãe; $\mathbf{C}$ - criança; $\mathbf{T}$ - terapeuta

TABELA 1

Sinais gráficos usados na transcrição e suas respectivas significações segundo a NURC:Mãe

\begin{tabular}{c|l}
\hline Sinal gráfico & \multicolumn{1}{c}{ Significação } \\
\hline$(())$ & ações, acontecimentos não verbais \\
\{ & ação ou verbalização concomitante \\
+ & pausa \\
$:$ & prolongamento de vogal \\
$/$ & truncamento (interrupção da cadeia significante) \\
\hline
\end{tabular}

\section{Discussão}

A seguir, faremos o primeiro recorte, mostrando como a mãe parece iniciar um processo de simetria dialógica, mas interrompe frequentemente as ações da criança, concluindo-as em seu lugar. 
M. e C. estão sentados no chão, onde se encontram alguns brinquedos:

M. $\{$ o cacá $?$ + o cavalo $?+$

C. ((manipula um cavalo de brinquedo em miniatura, fazendo-o andar. Em seguida, o joga para o lado, derrubando-o)).

M. $\quad$ põe o: + põe o moço pra andar a cavalo + põe! ++ senta o moço no cavalo! + ((diz isto mexendo nos braços e nas pernas de um boneco, abrindo-as para facilitar a sua colocação sobre o cavalo e o entrega a C., que estava observando a mãe))

C. ((pega o cavalo que estava jogado do seu lado esquerdo e, em seguida, pega o boneco da mão de M. Faz, então, o que M. havia solicitado))

M. \{ vamu sentá o moço + ((ajuda C. segurando o cavalo para mantê-lo em pé $))$

C. ((tenta colocar o boneco sobre o cavalo $))$

M. $\{$ assim + deixa a mamãe ajudar aqui ó $++++(($ pega o cavalo e o boneco das mãos de C.))

M. i::sso! ((ao encaixar o boneco sobre o cavalo))

As ações da criança, destacadas em negrito, mostram como no início da brincadeira ela encontrava-se ativa, tentando estabelecer algumas relações e contatos com os objetos. A mãe, a princípio, aproveita o que a criança inicia e acrescenta o significante "o moço" (boneco) na brincadeira, trazendo uma proposta e ampliando as possibilidades de manipulação e brincadeira do filho. Todavia, assim que a criança tenta colocar o boneco sobre o cavalo, a mãe intervém e toma a ação para si.

A mãe, ao dizer "deixa a mamãe ajudar aqui", pegando o cavalo e o boneco das mãos do filho, não só antecipa uma ação da criança, mas também toma o lugar dela como interlocutor ativo na relação e a coloca em uma posição de espectador. A criança ainda não havia solicitado ajuda, pois nem teve tempo de experimentar a situação, que foi concluída pela mãe ao dizer "Isso!".

Retomando o conceito bakhtiniano (BAKHTIN, 1997) sobre "uma atitude responsiva ativa" do adulto em relação à criança, notamos que, do modo como agiu, essa mãe não permitiu ao filho ocupar um lugar de autor de seu discurso. A ação da criança foi ignorada pela mãe, atitude frequente dos pais em relação aos seus filhos que apresentam Retardo de Linguagem (FERRIOLLI, 2003). 
A mãe, ao determinar as atividades durante o "brincar", constrói uma posição para a criança que é a de observador passivo: a mãe fala (o tempo todo) e a criança silencia. Percebe-se uma ruptura constante na relação dialógica estabelecida entre os parceiros, o que caracteriza uma assimetria e, portanto, uma desconstrução na linguagem. Observamos nitidamente, nesse caso, a relação dialética construída entre o dizer (da mãe) e o silêncio (do filho).

Com isso, ao clínico cabe compreender os momentos de silenciamento da criança com retardo de linguagem não apenas como "falta" de sintagmas e/ou léxico, mas também remetendo a "posições discursivas" (TFOUNI; PANTONI, 2004; FOUCAULT, 1972) - desse sujeito em relação ao seu parceiro.

No recorte abaixo, a mãe, parecendo ignorar o fato de a criança estar com a atenção focada em outro lugar, continua suas verbalizações.

C. ((olha para a filmadora e em seguida olha para o boneco sobre o cavalo que M. está segurando))

\section{M. é o papai que tá sentado no cavalo.}

M. ((afasta o cavalo de C. e o traz para perto como se estivessem cavalgando. Ao mesmo tempo fala)) pocotó pocotó pocotó pocotó pocotó ((em intensidade vocal mais baixa))

C. $\{(($ observa o cavalo, olha para M. e volta a observar o cavalo $))$

M. e o João? + vai andar a cavalo com o papai? +

M. aqui o Joãozinho + ó o nenê + ó o João ((pegando um outro boneco, menor que o primeiro e o coloca sobre o cavalo também))

M. ó o minininho + vai andar a cavalo + olha lá!

M. vai ((faz gesto com a mão, incentivando C. a pegar o cavalo com os bonecos)) + leva o nenê pra andar a cavalo leva! + segura o cavalinho ((faz o mesmo gesto novamente))

C. ((até o momento estava acompanhando os movimentos que M. vinha fazendo com o cavalo. Pega o cavalo com a mão direita, segurando-o apoiado no chão. Em seguida, puxa o cavalo para cima, derrubando os dois bonecos e afastando o boneco maior para o seu lado esquerdo))

M. ih::: no:ssa caiu: ++ coitado do João! 
M. ((pega o boneco menor que estava caído no chão)) põe o nenê pra dormir + põe o nenê na caminha pra dormir, põe! ((entregando o boneco menor na mão de C.))

C. ((pega o boneco menor da mão de $\mathrm{M}))$.

A mãe constrói sua narrativa com base em seu imaginário, da forma como é afetada pelos acontecimentos históricos (interdiscurso), da representação que faz dos objetos e dos papéis sociais de cada um dos membros de sua família. Com esses elementos, é construído um intradiscurso (materialidade concretizada pelas palavras de um enunciado) ou eixo sintagmático e metonímico (LACAN, 1998; CAMPOS, 2005), pelo qual a mãe manifesta o seu desejo.

Articulada à construção sintagmática, encontra-se a seleção no eixo paradigmático (eixo da seleção de Jakobson, 1995), por meio do qual o léxico torna-se presente na construção discursiva do sujeito. No primeiro recorte, a mãe utiliza o significante "moço", que é deslocado para o significante "pai" no recorte anterior. Nessa metáfora fica deflagrado o imaginário da mãe, pelo qual o pai ocupa o lugar de "cavaleiro", aquele que conduz as rédeas, levando o filho na garupa. Dentro dessa construção "fictícia", a mãe insiste em que a criança segure e sustente esses papéis que ela instaurou para os personagens, o que se concretiza no uso dos verbos no imperativo "vai", "leva", "segura", "põe".

Na sequência, a criança passa de "João" para "Joãozinho", "nenê", "menininho", demonstrando o lugar em que ela é posta pelo outro. O uso do diminutivo parece remeter a mãe ao significante "nenê" e é na contiguidade dos significantes que compreendemos a "posição-sujeito" (FOUCAULT, 1972) possível à criança. Ao falar "X", o sujeito deixa de falar "Y", ou seja, anuncia lugares possíveis e silencia outras instâncias discursivas (PÊCHEUX, 1997). Nesse caso, quando a mãe fala "nenê", ela explicita a representação que faz do filho. Ainda segundo Foucault (op. cit.), o indivíduo humano só pode ser agente de uma prática se se revestir de uma "forma-sujeito", que é a forma de existência histórica de qualquer indivíduo, agente das práticas sociais.

Por meio da observação dos gestos e expressões de João, na materialidade discursiva (por um modo não verbal), percebemos que ele se mobiliza mais do que a mãe em relação a compartilhar as ações (a criança, quando se dirige à mãe, oferece os objetos, sorri, parece fazer um convite; enquanto nas falas da mãe fica um tom impositivo! Imperativo!). 
Quando a mãe não percebe a intenção do filho, este "desmancha" o que é posto por ela, por exemplo, quando joga o cavalo e os bonecos no chão. Nesse momento, a mãe diz: "ih::: no:ssa caiu: ++ coitado do João!", fazendo referência ao acontecimento como algo externo à ação do filho já que a mãe seleciona o verbo "cair" e o flexiona com o pronome "ele caiu" (moço) deixando de pontuar a ação como sendo do filho, por exemplo, "você derrubou".

Na continuidade, enquanto a criança manipula um objeto, a mãe pega uma boneca e fala com o filho usando um tom mais agudo na voz e uma curva entonativa como se fosse a própria boneca. O recorte discursivo encontra-se abaixo:

C. olhando para a filmadora ((segura e manipula uma miniatura de armário em sua mão esquerda))

M. \{ oi! João + oi! João ((ao segurar uma boneca sobre o chão, aproximandoa de C. Fala alterando os aspectos prosódicos de sua fala))

C. ((olha para a boneca, pegando-a da mão de M. e a aproxima da miniatura de armário que já estava segurando))

M. $\quad$ quem que é essa aqui? ((aponta para a boneca)) + a mamãe? ((olha para o rosto de C.))

C.

$\{(($ joga a boneca para um lado e o armário para o outro. Em seguida, olha e sorri para M.))

Pôde ser identificado, por meio do corpus acima, que mãe e filho não interagem e não constroem enunciados (verbais ou não verbais) como se fossem duas linhas paralelas, embora, em alguns momentos, ocorram tentativas de interação, porém não suficientes para construir um diálogo duradouro.

O esquema abaixo pode ilustrar o que está sendo dito:

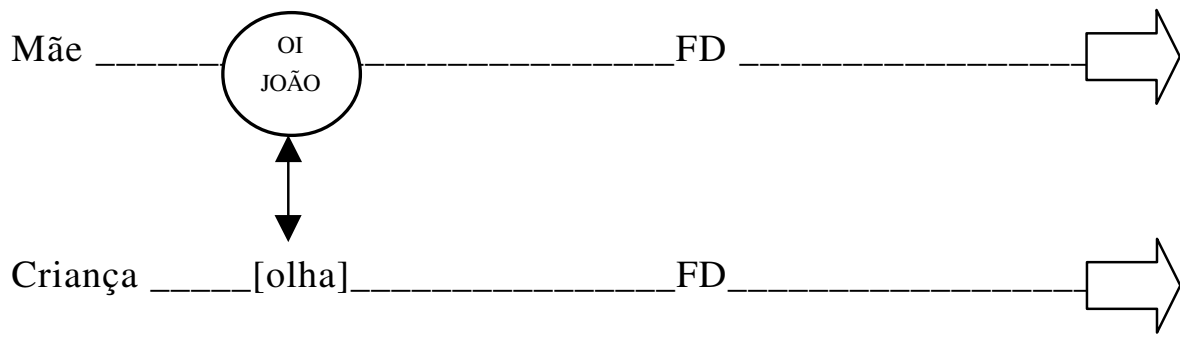


Quando a mãe fala “oi!", surge um prenúncio de interação com o filho (a boneca está falando com a criança). Parece que o filho aceita o "convite", pois olha para o que a mãe está mostrando e pega a boneca. Todavia, logo em seguida, joga o armário e a boneca, um para cada lado. Nesse momento, a criança demonstra estar presente e diz, pela sua ação, ser um sujeito "que faz", subvertendo, cindindo a proposta da mãe. Na continuidade, a criança sorri, momento em que se instaura uma nova "ponte" entre os dois. Contudo, a interação retorna ao paralelismo anterior (exposto no esquema apresentado), quando a mãe diz:

M. ((pega um objeto que estava caído atrás de C. e, ao colocá-lo na frente de C., diz:)) vamu arrumá o quartinho?

C. $\{(($ pega a miniatura de armário que havia jogado de lado, no chão, e a manipula))

M. vamu arrumá aqui o guarda-roupa a caminha ++ olha lá ((faz a ação que está descrevendo verbalmente))

C. $\{(($ continua manipulando o objeto, agora observando o que M. está fazendo) $)$

M. vamu sentá a Lívia aqui ó ++ vamu sentá a Lívi:a ((coloca uma outra boneca sentada numa miniatura de cadeira)) ++ vamu colocá /+ o Joãozinho vai naná ((coloca um pequeno boneco sobre uma miniatura de cama))

C. ((arruma o boneco que M. colocou na cama, como se estivesse encaixandoo na cama))

M. $\{(($ pega uma toalhinha que estava ao seu lado e a segura um pouco acima do chão e à frente da cama onde o boneco estava deitado)) nan/ cobre o nenê

M. cobre o nenê pra ele não sentir frio nana o nenê ((mantém a toalhinha erguida na mesma posição))

C. $\{(($ com a mão direita pega a toalhinha e a aproxima da cama. Então direciona a mão da

M., para que esta termine de cobrir o boneco))

M. i::sso! ((coloca a toalhinha sobre o boneco, ajeitando-a))

Até esse momento, a mãe desenvolve o brincar a sua maneira, a criança vai aceitando suas propostas e auxiliando a mãe na arrumação. No final, parece que a mãe fica satisfeita com o resultado ao dizer: "Isso!". 
Dentro das formações imaginárias ligadas à ideologia dominante, uma "boa família" é aquela que se encontra unida. E isso desponta, insistentemente, no brincar da mãe, pois o desejo não cessa de aparecer, já que desejo é falta (LACAN, 1999). Frequentemente a mãe falava com a terapeuta sobre a separação, questionando como ela se sentia incomodada com o atual casamento de seu ex-marido.

No trecho abaixo, a criança provoca outra cisão no discurso da mãe, quando olha e aponta para a filmadora. A mãe, porém, não atende a essa demanda trazida pelo gesto e olhar do filho e começa a perguntar "cadê o cavalo?".

C. ((manipula o objeto, observando o que M. está fazendo))

M. aqui é a mamãe +++ ((pegando a primeira boneca e uma cadeira, coloca a boneca sentada ao lado da "Lívia")) a mamãe o papai ++ ((pega um boneco e o coloca sentado))

C. $\{(($ olha para a filmadora $))$

C. ((aponta para a filmadora, olhando para M. e volta a olhar para a filmadora))

M. \{cadê o cavalo? (A mãe insiste em chamar a atenção da C. para o que ela pretende, ignorando para onde a $\mathrm{C}$. olha - a filmadora e a T. Nesse momento, a terapeuta fala com a criança)

T. a Bia + cê tá mostrando a Bia pra mamãe?

Parece que a mãe percebe a criança por meio do enunciado da T. e, então, diz para o filho:

\section{M. \{é a Bia!}

Com este último enunciado ocorreu um encontro entre a mãe e a criança, mas somente após a intermediação de uma terceira pessoa. O valor do enunciado (gesto e olhar) da criança foi dado pelo Outro (LACAN, 1998) presentificado na pessoa da terapeuta e por isso pôde ser acatado pela mãe. Salientamos que esse é um importante papel do terapeuta da linguagem, qual seja, instaurar a criança em outra posição-sujeito (e, consequentemente, em novas formações discursivas), na qual ela possa se compreender como sujeito ativo da e $n a$ linguagem. 
Durante a brincadeira constatamos que a mãe coloca a "filha" (boneca) sentada na cadeira e o "filho" (boneco) para dormir (aparecendo em dois dos recortes), o que pode representar posição de maior passividade para o filho, pois, se este é colocado para dormir, não pode atuar, mostrar sua vontade ou interagir. Acreditamos que exista uma assimetria dialógica que colabora para distanciar a criança de uma linguagem produtiva (desenvolvimento adequado da linguagem).

Parece haver um movimento (inconsciente) da mãe no sentido de conter as iniciativas do filho, ou seja, o que não faz parte do desejo materno não é percebido. Conforme dito anteriormente, o desejoé metonímico, vem por partes e ajuda a construir o sintoma, que é uma metáfora. Ferriolli (2003) anuncia que:

... a grande questão posta para o sujeito é ser ou não o falo, no entanto, escolher ser o falo ou não traz ao mesmo tempo uma passividade e uma atividade do sujeito, pois para Lacan (1999), não é o sujeito que irá conduzir-se, mas, de certa forma, será manipulado por seus pais através das 'cordinhas do simbólico' (FERRIOLLI, 2003, p.114).

No caso apresentado neste artigo, o retardo de linguagem é a metáfora que se constrói com base no desejo manifesto pela mãe, que passa a dominar, inconscientemente, o "espaço discursivo" do filho. A criança, na tentativa de ser amada, aceita essa condição e satisfaz (inconscientemente) o desejo da mãe. Podemos supor que a mãe sustenta a dificuldade do filho por questões relacionadas às suas fantasias e a um 'eu ideal' que emerge em seu discurso (real da língua).

\section{Considerações finais}

Concluímos que a mãe, por meio de seu imaginário e da narrativa construída no brincar, anuncia seu desejo de família unida (pai e filho andando a cavalo, a casa arrumada) e deixa emergir a imagem que faz de seu filho: um bebê passivo (que permanece deitado dormindo ou segue os comandos da mãe) com solicitações predominantemente imperativas, tais como "pega", "põe", etc.

Desse lugar em que a mãe se coloca (ou é colocada?), não percebe os movimentos que o filho faz para interagir e atuar sobre o mundo. Pelo discurso dela evidencia-se que essa criança acaba ocupando uma dependência dialógica em relação ao outro (que fala e age por ela). Ao ocupar essa "posição-sujeito", 
fica difícil para a criança deslocar-se para um outro lugar discursivo, seja de autor, seja de ator de suas iniciativas.

Dessa forma, acreditamos que o entendimento em relação ao atraso na aquisição da linguagem pela criança pode estar diretamente relacionado com o tipo de interação e de enunciação da criança e seus interlocutores de maior convívio. Sendo assim, o terapeuta deve ter uma escuta direcionada para a criança em seu contexto familiar desde o processo de avaliação, para que possam ser identificados os lugares discursivos possíveis a essa criança em seu ambiente.

Ancorando o seu "fazer" nos conceitos da Análise do Discurso, o fonoaudiólogo, além de identificar as chamadas "posições-sujeito", passa a ter maior silenciamento, adaptando-se à necessidade de escutar, com maior frequência, o discurso dos pais e dos sujeitos. Além disso, uma "rotina" de registro dos discursos deve ser adotada, para posterior análise, contribuindo tanto para a prática clínica como para pesquisas.

Entendemos que o terapeuta da linguagem, com base nesses princípios fundamentais da Análise do Discurso, também passa a ter condições de ocupar diferentes posições discursivas e, assim, favorece o deslocamento da criança para outros lugares dialógicos, a partir dos quais essa criança poderá construir novas possibilidades linguísticas.

\section{Referências bibliográficas}

AUTHIER-REVUZ, J. Heterogeneidade(s) enunciativa(s). Cadernos de Estudos Linguísticos, Campinas: Unicamp, v.19, p. 25-42, 1990.

BAKHTIN, M. Estética da criação verbal. São Paulo: Martins Fontes, 1997.

CAMPOS, C. M. A concepção de texto na aquisição de linguagem. Estudos Linguísticos XXXIV; 52 ${ }^{\circ}$ Seminário do GEL-Unicamp, Campinas, p. 123-128, 2005.

COURTINE, J. J. Définition d'Orientations Théoriques et Méthodologiques en Analyse de Discours. Philosophiques, Paris, v. IX, n. 2, 1984.

FERRIOLLI, B. H. V. M. Objeto do desejo: a manifestação metafórica e metonímica no retardo de linguagem. 220f. 2003. Tese (Doutorado) - FFCLRP-USP.

FERRIOLLI, B. H. V. M. Enfoque discursivo na clínica da gagueira. In: ROCHA, Eliana Maria Nigro. Gagueira: um distúrbio da fluência, 2007. Cap. 4, p. 83-104.

FERRAZ; FERRAZ, M. G. C. Sujeito psíquico e sujeito linguístico: uma introdução à psicologia aplicada à fonoaudiologia. Marília: Unesp Marília Publicações, 2001. 
FOUCAULT, M. Arqueologia do saber. Trad. Luiz Fernando Baeta Neves. Petrópolis: Vozes, 1972.

FOUCAULT, M. A ordem do discurso. São Paulo: Loyola, 2004.

JAKOBSON, R. Dois aspectos da linguagem e dois tipos de afasia. In: BLIKSTEIN, I. (Org.). Linguística e Comunicação. São Paulo: Cultrix, 1995. p.34-62.

KOMESU, F. C. Diálogo e dialogismo no processo de aquisição da linguagem. Alfa, São Paulo, n. 46, p. 55-70, 2002.

LACAN, J. A instância da letra no inconsciente ou a razão desde Freud. In: LACAN, J. Escritos. Rio de Janeiro: Jorge Zahar Editora, 1998. p.496-533.

LACAN, J. O desejo e o gozo. In: LACAN, J. O seminário: as formações do inconsciente, livro V. Rio de Janeiro: Jorge Zahar, 1999. p.261-279.

ORLANDI, E. P. Análise do discurso: princípios e procedimentos. Campinas: Pontes, 1999.

PALLADINO, R. R. R. Questões sobre o diagnóstico fonoaudiológico em crianças. Distúrbios da Comunicação, São Paulo: PUC, v. 11, p.111-124, 1999.

PÊCHEUX, M. Análise Automática do Discurso (AAD-69). In: GADET F.; HAK, T. (Org.). Por uma análise automática do discurso: uma introdução à obra de Michel Pêcheux. Trad. Eni Orlandi. Campinas: Unicamp, 1997. p. 61-151.

PRETI, D. (Org.). Análise de textos orais. Projetos Paralelos NURC I. São Paulo: Humanitas - USP; 2001. p. 7-10.

RESCORLA, L.; ROSS, G. S.; MACCLURE, S. Language Delay and behavioral/ emotional problems in toddlers: findings from two developmental clinics. J. Speech Language, and Hearing Research, n. 50, p.1063-1078, 2007.

SACHSE, S.; VON SUCHODOLETZ, W. Early identification of language delay by direct language assessment or parent report? J. Dev. Behav. Pediatr., n. 29, p. 34-41, 2008.

SAUSSURE, F. Objeto da linguística. In: SAUSSURE, F. Curso de linguística geral. 7 ed. São Paulo: Cultrix, 1975. p. 15-23.

SOBRINHO, A. Dizer o Dito - a questão da interpretação na fonoaudiologia. Distúrbios da Comunicação, São Paulo: PUC, v.8, p 23-39, 1996.

TFOUNI, L.V.; FERRIOLLI, B. H. V. M.; MORAES, J. A concepção de sujeito na clínica fonoaudiológica: a proposta de um novo paradigma. Pró-Fono Revista de Atualização Científica, Carapicuiba, SP, v. 14, n. 2, p. 275-282, 2002. 
TFOUNI, L.V.; PANTONI, R.V. Sobre a ideologia e o efeito de evidência na teoria da análise do discurso francesa. In: Resúmenes II Conferencia internacional "La obra de Carlos Marx y los desafios del siglo XXI”. Havana. p. 70, 2004.

TFOUNI, L. V.; FERRIOLLI, B. H. V. M. O discurso dos pais como resultado do discurso dos pais. In: DEL RÉ, A.; FERANADES, S. D. (Org.). A linguagem da criança: sentido, corpo e discurso. São Paulo: Cultura Acadêmica, 2008. p. 165-180. 